\title{
Pediatric DXA: clinical applications
}

\author{
Larry A. Binkovitz • Paul Sparke • Maria J. Henwood
}

Received: 27 December 2006 /Revised: 8 February 2007 / Accepted: 1 March 2007 / Published online: 13 April 2007

(C) Springer-Verlag 2007

\begin{abstract}
Normal bone mineral accrual requires adequate dietary intake of calcium, vitamin D and other nutrients; hepatic and renal activation of vitamin D; normal hormone levels (thyroid, parathyroid, reproductive and growth hormones); and neuromuscular functioning with sufficient stress upon the skeleton to induce bone deposition. The presence of genetic or acquired diseases and the therapies that are used to treat them can also impact bone health. Since the introduction of clinical DXA in pediatrics in the early 1990s, there has been considerable investigation into the causes of low bone mineral density (BMD) in children. Pediatricians have also become aware of the role adequate bone mass accrual in childhood has in preventing osteoporotic fractures in late adulthood. Additionally, the availability of medications to improve BMD has increased with the development of bisphosphonates. These factors have led to the increased utilization of DXA in pediatrics. This review summarizes much of the previous research regarding BMD in children and is meant to assist radiologists and clinicians with DXA utilization and interpretation.
\end{abstract}

Keywords DXA · Bone mineral density · Pediatrics · Osteoporosis

\section{A. Binkovitz $(\bowtie)$}

Department of Radiology, Columbus Children's Hospital,

700 Childrens Way,

Columbus, OH, USA

e-mail: binkovitz@yahoo.com

\section{P. Sparke}

Department of Chemistry, Capital University,

Columbus, OH, USA

\section{J. Henwood}

Department of Endocrinology, Columbus Children's Hospital,

Columbus, OH, USA

\begin{abstract}
Abbreviations
ALL acute lymphocytic leukemia

BMC bone mineral content

BMD bone mineral density

CF cystic fibrosis

CS corticosteroids

DXA dual energy X-ray absorptiometry

JRA juvenile rheumatoid arthritis

LS lumbar spine

TBBMC total body bone mineral content

TBBMD total body bone mineral density

WBI whole brain irradiation
\end{abstract}

\section{Introduction}

Peak bone mineral accrual occurs during early puberty and peak bone mass is achieved in young adulthood. Low BMD can result from a wide variety of childhood diseases or be due to the effects of their treatment. Increasingly, pediatric specialists are requesting evaluation of BMD and radiologists are expected to be knowledgeable in the technique, interpretation and clinical applications of DXA. A review of the technical and interpretive aspects of DXA has been recently presented [1]. The clinical uses of DXA in pediatrics are exceedingly broad. This paper reviews the clinical data regarding pediatric DXA and can be used to assist radiologists and clinicians in DXA utilization and interpretation.

\section{Gastrointestinal disorders}

Gastrointestinal diseases may impact bone health in several ways. Poor calcium intake, as in patients with a milk 
allergy, and reduced calcium absorption, as in patients with untreated celiac disease, result in low BMD. Early correction of the underlying deficiency allows normal bone mineralization to occur. In addition to poor calcium absorption, inflammatory bowel disease likely impacts bone health through other factors including chronic diarrhea, decreased lean tissue mass, reduced physical activity, increased inflammatory cytokines, and CS therapy. As in all chronic conditions, correction of short stature and delayed maturation will allow better identification of those patients with abnormal DXA findings who will have significant bone mineral deficits.

\section{Milk allergy}

Henderson and Hayes [2] reported a positive correlation between LS and hip BMD and calcium intake in children with significant milk allergy. They found a $5-8 \%$ increase in LS Z-scores and a 9-13\% increase in hip Z-scores in patients with daily calcium intake above the recommended dietary allowances. These findings were confirmed in children with reduced dairy intake due to a variety of other causes [3,4]. There was a positive correlation between BMD and calcium intake with normal values in the subgroup with normal dietary calcium intake and decreasing BMD as the daily intake of calcium decreased. LS BMD was maintained, even with severe dairy restrictions when calcium intake was maintained through diet or supplementation.

\section{Inflammatory bowel disease}

Boot et al. [5] found decreased LS and TBBMD in children with Crohn disease or ulcerative colitis. The decreases were statistically significant even when they accounted for the delayed bone age in their patients. Similarly, Ahmed et al. [6] found reduced LS and TBBMD Z-scores in nearly $70 \%$ of children with Crohn disease and, to a lesser extent, ulcerative colitis, when compared to healthy age-matched controls. However, when height was taken into account, only $22 \%$ of their patients had low BMD. Burnham et al. [7] found decreased height, lean tissue mass and TBBMC in children with Crohn disease when compared to normal controls. However, with correction for height, age, race, Tanner stage and lean tissue mass, no statistically significant differences were found between the study and control groups. The authors also found no correlation between CS treatment and height-corrected BMC. Similar findings were reported by Walther et al. [8]. Thus, in patients with inflammatory bowel disease, the apparent low LS BMD and TBBMC is largely a result of short stature, delayed maturation and decreased lean tissue mass.
Celiac disease

Kalayci et al. [9] found lower LS BMD in untreated celiac disease patients compared to treated patients. They found that nearly all children with celiac disease whose treatment began before the age of 4 years reached normal BMD compared to only $50 \%$ of children whose treatment began after the age of 4 years. They also found that all patients who initially presented with gastrointestinal symptoms had normal BMD after 1 year of a gluten-free diet. In prepubertal children with celiac disease, Barera et al. [10], Tau et al. [11] and Szathmari et al. [12] found an increase in height, weight, BMC and BMD after 1.5 years of a glutenfree diet when compared to baseline measurements. These reports indicate that in patients with celiac disease, normalization of DXA findings can be expected with early diagnosis and treatment.

\section{Liver disease}

The effects of liver dysfunction on bone health are complex and may involve vitamin malabsorption, failure of vitamin D activation, calcium malabsorption, bile salt deficiency and chronic malnutrition. Argao et al. [13] evaluated children with a variety of chronic cholestatic liver diseases and found distal radial BMC to fall quickly after birth and in infancy. The values remained low throughout childhood and reflected the severity of the underlying hepatic dysfunction. In a study of prepubertal children with Alagille syndrome, Olsen et al. [14] found reduced height, weight and TBBMC compared to healthy controls matched for age, gender, ethnicity and physical maturity. Malabsorption of fat-soluble vitamins, particularly vitamin $\mathrm{D}$, significantly reduces LS and TBBMC. D'Antiga et al. [15] found normal LS BMC and BMD in patients with childhood liver failure who were at least 1 year out from orthotopic liver transplantation. Return to normal values appeared to be unaffected by the severity of bone disease or cholestasis prior to transplantation. Thus, liver dysfunction with disordered vitamin D metabolism results in early decreased bone mineral accrual. With successful liver transplantation, normalization of DXA findings can be expected.

\section{Renal diseases}

Chronic kidney disease results in abnormal bone metabolism via disturbances in calcium and phosphate handling, altered vitamin D and parathyroid hormone levels and function, and altered renal clearance of other metabolites. Additional factors that affect the BMD in these patients include malnutrition, metabolic acidosis, anemia and 
growth hormone abnormalities resulting in growth retardation. As with many chronic medical conditions, short stature will greatly affect BMD and needs to be accounted for in DXA interpretation.

Bakr [16] found reduced LS BMD in $60 \%$ of pre- and postdialysis patients. The degree of osteopenia correlated with biochemical markers of secondary hyperparathyroidism. However, the DXA BMD values were not corrected for height. Similar results were reported by Pluskiewicz et al. [17] following a 2-year longitudinal study of adolescents with chronic kidney disease. They found decreased or stable LS BMD (uncorrected for height) during a time when an increase would be expected. The most severe decreases in BMD were found in patients who were treated with CS. In contrast, Ahmed et al. [18] found normal TBBMD and TBBMC as well as normal LS BMD in children with chronic kidney disease when the DXA values were corrected for height. Similar findings were reported in children before transplantation [19]. Boot et al. [20] reported normal LS and TBBMD in patients with kidney disease of relatively short duration and in the setting of adequate vitamin D replacement. Two-year follow-up of these patients demonstrated continued maintenance of normal BMD [21]. Several authors found that the height-corrected LS BMD was reduced for up to 2 years after transplantation; this was felt to be due to high-dose CS treatment required to suppress transplant rejection. However, by 3 years after transplantation, LS BMD had recovered to normal values [18, 22-24].

Idiopathic hypercalciuria results in excessive urinary excretion of calcium and has increasingly been identified as a cause of decreased BMD in children [25-28]. The degree of BMD reduction does not appear to correlate with the presence of urolithiasis or urinary uric acid concentration. Studies of children and their mothers with idiopathic hypercalciuria indicate that low LS and hip BMD persist into adulthood $[25,26]$.

In summary, the various metabolic disturbances resulting from altered renal physiology may compromise normal bone mineralization and remodeling, but children with chronic kidney disease often maintain normal BMD if calcium and vitamin D metabolism are normal. CS treatment, either before transplantation or when used to suppress transplant rejection, appears to contribute to low BMD but short-term follow-up indicates eventual normalization of LS BMD. Regardless of the nature of renal disease, correcting for height is essential for accurate interpretation of DXA results in these patients.

\section{Endocrinological diseases}

Skeletal development is significantly influenced by multiple hormone systems that are essential to normal bone mineral accrual. Both insufficient and excessive hormone levels can have deleterious effects, resulting in inadequate bone formation or disproportionate bone resorption. Pubertal hormones play a critical role in bone mass acquisition with major differences occurring based on sex and skeletal site [29]. Patients with early or delayed puberty will show early or delayed peak bone mass accrual, respectively [30]. Treatment of precocious puberty includes gonadotropinreleasing hormone analogs that could theoretically interfere with normal bone mineral acquisition. Short-term treatment does not interfere with normal BMD increases in these patients [31].

Disorders of growth hormone, insulin and glucocorticoids

Accurate DXA evaluation of children with growth hormone deficiency or idiopathic short stature must account for their smaller bones [1]. Children with growth hormone deficiency will present with low areal [32] and volumetric LS [33] BMD when first diagnosed. Children with idiopathic short stature have also been found to have low areal LS and hip BMD prior to therapy [34]. With sustained growth hormone replacement these values have been reported to remain stable [33] or normalize rapidly [34]. Children with growth hormone deficiency have a robust response to replacement therapy with increases in height, lean tissue mass and TBBMC [33]. Increases in BMD occur even after peak height is achieved, and this indicates the need to continue hormone therapy until peak BMD is achieved $[35,36]$.

Type 1 diabetes mellitus is a known risk factor for osteoporosis, but the underlying mechanisms are not fully determined. Adolescent patients have lower bone mass and bone size despite normal growth and maturation [37]. Studies suggest that children and adolescents with diabetes have reduced bone formation and increased bone resorption resulting in low bone mass and BMD [38, 39]. Hemoglobin A1C level, a measure of glycemic control, negatively correlates with BMD [40] and TBBMC [41].

The negative effects of chronic high-dose CS therapy on bone have been well documented. CS replacement therapy, as in congenital adrenal hyperplasia, has not been found to result in reduced BMD [42, 43]. However, young women with congenital adrenal hyperplasia are at risk of reduced BMD if there is biochemical evidence of androgen suppression due to CS therapy [44]. Patients with either childhood-onset or adult-onset Cushing disease often have severe reductions in BMD due to increased osteoclastic activity and bone resorption with normal or reduced bone deposition [45]. Additionally, concomitant reductions in sex and growth hormones contribute to their low BMD. Adolescents appear to be particularly vulnerable to reduced trabecular bone density as measured at the LS. BMD deficits and biochemical measures of bone turnover showed 
marked improvement after 2 years remission from hypercortisolism when compared to baseline values, but low LS BMD persisted in the majority of patients [46].

\section{Disorders of reproductive hormones}

Reproductive hormones play an important role in the acquisition of bone mineral; estrogen is known to have a protective effect against the development of osteoporosis in postmenopausal women. The effects of hormonal birth control use on BMD in adolescent girls have been investigated by several researchers. The trend toward lower estrogen levels in oral contraceptives has been associated with decreased BMD in adolescent girls who use oral contraceptives [47, 48]. Progesterone-mediated contraceptives (Depo-Provera) have been shown to inhibit bone mineral acquisition in the LS and hip in adolescent girls [49-51]. The extent of this reduction appears to correlate with the duration of treatment and can be lessened with supplemental estrogen [51]. Partial or full BMD recovery can occur after cessation of treatment and can be facilitated with increased physical activity and adequate calcium and vitamin D intake.

Girls with anorexia nervosa have been found to have decreased BMD at multiple skeletal sites [52-54]. These reductions are thought to be due to a combination of nutritional (decreased calcium and caloric intake), hormonal (decreased estrogen levels, delayed puberty), and mechanical (decreased lean tissue mass) factors. With resumption of normal caloric intake and return of menses, there is biochemical evidence of increased bone turnover; however, BMD levels remain low and Z-scores may continue to fall for at least 1 year [53]. It is not known if full BMD recovery will occur by early adulthood, but adult women who had adolescent-onset anorexia nervosa have more dramatic reductions in BMD than those with onset during adulthood $[55,56]$. Estrogen replacement with oral contraceptives and vigorous exercise can protect against BMD loss in anorexia nervosa [57].

Untreated congenital hypothyroidism can result in markedly reduced BMD. Children with adequate long-term thyroid replacement therapy show normal LS and hip BMD and BMC [58, 59] and normal findings continue into young adulthood [60]. Later in childhood, hypothyroidism is usually caused by Hashimoto thyroiditis. LS and distal radial BMD are expected to be normal at diagnosis and to be maintained with thyroid hormone therapy, and normal peak bone mass is to be expected in these patients [61]. Hyperthyroidism in Graves disease markedly decreases LS and hip BMD, but these normalize within 1 year following thyroid ablation and hormone therapy [62].

In summary, hormonal imbalances from any of a large number of endocrine disorders are associated with abnor- mal DXA findings and reduced BMD. With hormone replacement therapy, improved bone mineral accrual is to be expected in most of the endocrine deficiencies. However, with anorexia nervosa, especially with onset in adolescence, there appears to be a sustained reduction in BMD even after resumption of normal caloric intake and menses.

\section{Respiratory diseases}

\section{Cystic fibrosis}

In cystic fibrosis (CF), low BMD may be caused by reduced gastrointestinal absorption of calcium and vitamin $\mathrm{D}$, reduced testosterone levels, chronic hypoxia, chronic CS use, and reduced lean tissue mass. Because of the multifactorial nature of reduced BMD in $\mathrm{CF}, \mathrm{BMD} Z$-scores often reflect the severity of illness. Clinically stable children with mild CF have been shown to have normal BMD [63-65]. However, adolescents and adults with CF have accelerated bone loss over time reflecting disease progression [66, 67]. Henderson and Madsen [68] and Buntain et al. [66] found progressively decreasing BMD Z-scores with increasing age in CF patients. LS, hip and TBBMD in the prepubertal group were normal. TBBMD was reduced in adolescents; however, all other sites remained normal. In adult patients, BMD was reduced at all sites. In a follow-up study, Haworth et al. [69] reported that patients older than 25 years showed accelerated LS and hip BMD losses. Bhudhikanok et al. [70] found that LS, hip, and TBBMD were low at baseline and documented further bone loss at follow-up. CS use was identified as the most modifiable factor accounting for this bone loss and the authors suggested that bisphosphonates may be beneficial in these patients. The benefits of bisphosphonates in CF were confirmed by Aris et al. [71, 72] and Haworth et al. [73] who found increases in LS and hip BMD following treatment with intravenous or oral bisphosphonates, respectively.

\section{Asthma}

Asthma may inhibit normal bone metabolism due to chronic hypoxia and decreased physical activity. Additionally, asthmatic patients are treated with both oral and inhaled CS to reduce airway inflammation. Patients treated with low or moderate levels of inhaled CS have been shown to have normal BMD Z-scores when compared to CS-naive asthmatic controls but reduced BMD Z-scores when compared to normal controls when height is not taken into account [74-77]. Allen et al. [78] and Harris et al. [79] found significant reductions in BMD in asthmatic children receiving high doses of inhaled CS. 


\section{Hematological diseases}

Anemia and hemophilia

Chronic anemias can affect bone structure and density through bone marrow hyperplasia (resulting in expansion of the medullary space, trabecular coarsening and cortical thinning), and vasoocclusion (resulting in medullary and diaphyseal infarction). Additional factors for reduced BMD include reduced lean tissue mass, decreased physical activity and hypogonadism, and in the case of thalassemia, endocrine dysfunction. Brinker et al. [80] found low BMD in children with sickle cell anemia. These findings confirmed those of Soliman et al. [81] who reported low LS BMD in prepubertal children with sickle cell anemia. Lal et al. [82] and Buison et al. [83] noted markedly reduced BMD and BMC, which correlated with disease severity in these children. These changes were found to persist into adulthood [84]. Additionally, low calcium intake and low vitamin D levels may contribute to decreased BMD in these patients. Vogiatzi et al. [85] and Benigno et al. [86] evaluated children with thalassemia major who were fully treated with transfusion and chelation therapy and found reduced BMD at diagnosis and showed further reductions at follow-up.

Patients with hemophilia are at risk for osteoporosis due to reduced levels of physical activity and sports, particularly those involving running, jumping and axial loading of the skeleton. The severity of hemophilic arthropathy can be quantitated using a clinically derived joint score, and this has been found to correlate with BMD [87]. Low BMD is independent of height and weight but correlates with disease severity and extent. These changes can be expected to persist into adulthood [88].

\section{Oncological diseases}

Acute lymphocytic leukemia

ALL is the most common childhood malignancy, but because of its excellent prognosis, most children with ALL survive into adulthood. Arikoski et al. [89] found reduced BMD in ALL survivors up to 20 years after treatment. Of their 29 patients, 20 had received cranial irradiation and four males had received testicular irradiation. The use of highdose methotrexate and cranial irradiation were found to be significantly correlated with low BMD. Differing results were presented by Brennan et al. [90] who also reported significantly reduced LS, hip and distal radial BMD in longterm survivors of ALL but found no statistically significant correlation of BMD with cranial irradiation, growth hormone status or height Z-scores. They suggested that the low BMD found in their patients was related to the effects of chemotherapy rather than cranial irradiation. Van der Sluis et al. [91] found normal LS and TBBMD a mean of 10 years after ALL treatment that included high-dose methotrexate and CS but not cranial irradiation. Their patients had all been prepubertal at the time of initial diagnosis and none had signs of significant gonadal or growth hormone dysfunction at the time of follow-up. The authors concluded that the deleterious effects of ALL and its treatment in childhood on BMD may be due to cranial irradiation but, in its absence, BMD will normalize by early adulthood. This conclusion is supported by other researchers [92, 93]. Jarfelt et al. [94] examined bone turnover and growth hormone status with respect to physical activity levels and BMD in adult survivors of childhood ALL. The patients were all prepubertal at the end of treatment and had been treated with high doses of CS and methotrexate. No patient had evidence for gonadal or endocrine dysfunction. The BMD values were normal for the group. Only the level of physical fitness at follow-up correlated positively with BMD. The authors stressed the importance of physical activity in restoring and maintaining normal BMD in survivors of childhood ALL.

In summary, children with ALL will have reduced BMD during treatment and shortly thereafter. The recuperative capacity in young children is high and normal BMD should be expected even after high-dose methotrexate and CS therapy. The role of adequate physical activity is being increasingly stressed as an important factor in normal BMD recovery. Children who have survived ALL may be at risk of persistently low BMD in adulthood if they have confounding factors such as gonadal dysfunction or if the course of their disease coincided with the period of expected rapid accrual of bone mineral that normally occurs during puberty.

\section{Other malignancies}

There are only limited data regarding the effects of other childhood malignancies on BMD. Aisenberg et al. [95] and Vassilopoulou-Sellin et al. [96] found reduced femoral neck and TBBMD in young adult survivors of various childhood cancers. Gonadal dysfunction due to pelvic or cranial irradiation was the factor most strongly correlated with reduced BMD. CS treatment did not correlate with low BMD. Nysom et al. [97] reported normal size-adjusted TBBMC in adult survivors of childhood lymphoma and found no relationship between TBBMC and cumulative methotrexate or CS doses. Kelly et al. [98] evaluated adult survivors of various pediatric solid tumors and found reduced BMD in at least one site in half of their patients. Only the total number of chemotherapeutic agents correlated with reduced BMD. Five of six extremities involved with a bone sarcoma showed reduced BMD. Similar results 
were found in a group of sarcoma survivors reported by Ruza et al. [99]. Interestingly, they found that those diagnosed prior to puberty had more severe BMD reductions later in life. This may be due to the extensive physical disabilities associated with amputations and limb salvage procedures in these patients. Odame et al. [100] found that patients with childhood brain tumors treated with cranial irradiation had reduced LS and TBBMD and these were correlated with reduced physical activity and poorer quality of life. The authors postulated that the higher cranial radiation doses used for the treatment of brain tumors had a profound effect on long-term BMD compared to the relatively lower doses used in the treatment of ALL.

In summary, there are multiple factors that affect short- and long-term BMD in these patients/survivors. These include pubertal status at diagnosis, type of malignancy, local (sarcomas, central nervous system tumors) versus systemic (leukemia) disease, initial (malnutrition, immobilization) versus prolonged (amputation) disease-related disability, types of chemotherapy, and radiation ports and dosages that may cause gonadal or growth hormonal dysfunction.

\section{Neurological diseases}

Cerebral palsy

Because of decreased muscle development and ambulation, children with cerebral palsy are at increased risk of osteoporosis-associated fractures. Frequently, assessment of the LS and hips with DXA is impossible due to difficulties in positioning patients with contraction deformities, muscular spasm-induced motion artifacts or orthopedic hardwarerelated artifacts. Because of these limitations, Harcke et al. [101] suggested scanning the distal femur with these patients positioned on their side. Distal femoral BMD was found to be highly correlated with hip BMD and the technique yielded highly reproducible BMD data [102].

Henderson et al. [103] demonstrated reduced LS and hip BMD in children with cerebral palsy. Measures of nutritional and ambulatory status were found to be the best predictors of BMD. In children with moderate to severe disease, Henderson et al. [104] found distal femur and LS BMD to be markedly reduced and both closely correlated with disease severity. Distal femoral BMD was negatively correlated with age, indicating progressive bone mineral deficits as these children grew older. The lack of a strong correlation between LS BMD and fracture risk in the lower extremities emphasizes the need for direct assessment of the distal femur with DXA in these patients. In a prospective longitudinal study of patients with cerebral palsy, Henderson et al. [105] found that low initial LS and distal femur BMD $\mathrm{Z}$-scores were associated with poor growth, nutritional status and motor function, and these contributed to reduced bone mineralization at follow-up. Treatment with bisphosphonates for 1 year resulted in a substantial increase in distal femoral BMD in children with quadriplegic cerebral palsy [106]. The improvement was sustained for at least 6 months after the last treatment. However, Bachrach et al. [107] found that LS BMD returned to baseline values 2 years after bisphosphonate therapy was terminated. Importantly, despite the lack of sustained BMD improvement, no patient had a fracture during the treatment or follow-up periods.

In summary, children with $\mathrm{CP}$ show decreased bone mineral status that reflects the duration and severity of their disease. Distal femoral measurements better reflect the bone status at the sites more at risk of fracture. Bisphosphonate therapy increases BMD during treatment and it appears to have sustained benefits with reduced fracture rates even after treatment is terminated.

\section{Meningomyelocele}

Quan et al. [108] found reduced forearm BMD in children with meningomyelocele. Patients with a history of fracture had substantially lower forearm BMD than those without a fracture history. The reduced upper extremity BMD in these patients with preserved upper extremity function may indicate that both systemic and local factors affect bone mineralization. Hypercalciuria in nonambulatory patients with meningomyelocele may be such a factor. Quan et al. [109] later evaluated the effect of thiazide treatment for hypercalciuria in these patients and found no change after 1 year in forearm BMD when compared to placebo-treated controls. Valtonen et al. [110] found normal forearm and LS BMD in adult patients with meningomyelocele, but reduced hip BMD in one-third of the patients. There was a trend for low hip BMD in the nonambulatory compared to ambulatory patients but not for the LS. This dissociation of LS and hip BMD values was thought to be due to relatively preserved axial loading on the LS in upright patients with meningomyelocele. The normalization of forearm BMD in these adult patients was attributed to increased upper extremity muscular stress with the use of crutches and manual wheelchairs.

\section{Connective tissue diseases}

Juvenile rheumatoid arthritis and systemic lupus erythematosus

Rheumatoid diseases have long been known to affect bone health negatively. Disease extent, severity, subsequent disability and CS therapy negatively impact bone mineralization. Pepmueller et al. [111] and Pereira et al. [112] 
found decreased regional, LS, and TBBMD in patients with JRA. The decrease was more severe in children with longer disease duration and was similar for oligoarthritis and polyarthritis. Lien et al. [113] found decreased TBBMC and TBBMD in patients with juvenile idiopathic arthritis. Disease duration and severity correlated with TBBM but not CS therapy. Henderson et al. [114] found no statistically significant difference in TBBMD in prepubertal children with mild-to-moderate JRA and no history of CS treatment when compared to normal controls. When a similar study was performed on CS-naive older girls with mild-tomoderate JRA, Henderson et al. [115] found decreased TBBMC. As with other chronic diseases of childhood, it appears that persistent disease activity through puberty results in decreased BMC. Mul et al. [116] found marked reductions in $\mathrm{LS} \mathrm{BMD}$ and $\mathrm{BMC}$ in children with rheumatic diseases treated for at least 1 year with high-dose CS. Bianchi et al. [117] found that long-term methotrexate for JRA did not result in reduced LS or TBBMD.

In summary, prepubertal children with JRA of mild or moderate severity without a history of CS treatment will have TBBMD similar to healthy children. With increasing disease severity and duration, especially through puberty, TBBMC will decrease when compared to normal children.

These changes are in contrast to the normal DXA findings reported in patients with juvenile systemic lupus erythematosus [118, 119]. Unlike patients with JRA, these patients typically do not have bone and joint involvement and thus are more likely to have preserved BMD. However, factors that may negatively impact bone health in these patients include immobility, limited exposure to sunlight, and CS therapy.

\section{Musculoskeletal diseases}

For normal mineralization to occur, adequate muscleinduced mechanical stresses are required to induce bony remodeling. Insufficient muscle mass and activity result in poor bone accrual and low BMD. Additionally, therapy of primary muscle disorders with CS also inhibits normal bone mineralization.

Duchenne muscular dystrophy and dermatomyositis

In a longitudinal study of boys with Duchenne muscular dystrophy, Larson and Henderson [120] found that LS and hip BMD correlated with functional mobility level with ambulatory boys having higher LS BMD than nonambulatory boys. Hip BMD was decreased before loss of ambulation and showed progressive reduction over time. Fractures occurred in nearly half of patients, most typically involving the lower extremity and frequently resulting in loss of ambulation. Bianchi et al. [121] found decreased LS and TBBMD in ambulatory boys with Duchenne muscular dystrophy when compared to healthy boys. LS BMD was more severely reduced in the subset of Duchenne muscular dystrophy patients treated with CS. The authors noted greater lower extremity than upper extremity bone mineral loss using regional DXA analysis, especially in the CS-treated patients, and they attributed this to reduced mechanical stress on the lower extremities. Hawker et al. [122] found an increase in LS and TBBMD after 2 years of bisphosphonate treatment, supplemental calcium, and vitamin D. Improvement in TBBMD was inversely related to age at baseline.

In summary, patients with Duchenne muscular dystrophy have reduced LS BMD, especially in the setting of CS treatment. The low LS and hip BMD worsen with loss of ambulatory status and are frequently associated with fractures of the lower extremities.

Studies of a small number of children with dermatomyositis have found low LS BMD that worsens with ongoing CS therapy [123, 124]. Patients treated with bisphosphonates for osteoporosis-related compression fractures show increases in LS BMD [123].

\section{Osteogenesis imperfecta}

Osteogenesis imperfecta includes a spectrum of genetic disorders of collagen synthesis resulting in abnormal skeletal and connective tissues. Reduced BMD and other factors result in fragile bones and multiple fractures. Fracture occurrence and DXA findings in these children vary with subtype with few fractures and normal or nearnormal DXA findings in type I osteogenesis imperfecta and more frequent fractures and marked reductions in BMD in types III and IV [125, 126]. (Type II typically results in perinatal demise.) Since as many as $40 \%$ of patients with osteogenesis imperfecta will have normal BMD and BMC, a normal DXA study does not preclude this diagnosis or distinguish these cases from non-accidental injuries [125]. In recent years, clinical trials using bisphosphonates in osteogenesis imperfecta have yielded impressive results with multiple studies demonstrating increases in LS, hip and TBBMD and improved quality of life [127-130]. Patients with the lowest baseline bone mass experienced the most significant gains with treatment. Improved mobility, ambulation, muscle force and reduced chronic pain and fatigue lead to improved quality of life, and the stimulus of physical activity is known to be beneficial to bone. Increased bone mass in the skull following bisphosphonate therapy in these patients implies that the drug also has a direct effect on bone accrual irrespective of physical activity [129]. The theoretical concern that this therapy might negatively impact linear growth in these children has not been shown to be true [131]. 


\section{References}

1. Binkovitz LA, Henwood MJ (2007) Pediatric DXA technique and interpretation. Pediatr Radiol 37:21-31

2. Henderson RC, Hayes PRL (1994) Bone mineralization in children and adolescents with a milk allergy. Bone Miner 27:1-12

3. Infante D, Tormo R (2000) Risk of inadequate bone mineralization in diseases involving long-term suppression of dairy products. J Pediatr Gastroenterol Nutr 30:310-313

4. Rockwell JE, Williams SM, Taylor RW et al (2005) Two-year changes in bone and body composition in young children with a history of prolonged milk avoidance. Osteoporos Int 15:1016-1023

5. Boot AM, Bouquet J, Krenning EP et al (1998) Bone mineral density and nutritional status in children with chronic inflammatory bowel disease. Gut 42:188-194

6. Ahmed SF, Horrocks IA, Patterson T et al (2004) Bone mineral assessment by dual energy $\mathrm{x}$-ray absorptiometry in children with inflammatory bowel disease: evaluation by age or bone area. $\mathrm{J}$ Pediatr Gastroenterol Nutr 38:276-281

7. Burnham JM, Shults J, Semeao E et al (2004) Whole body BMC in pediatric Crohn disease: independent effects of altered growth, maturation, and body composition. J Bone Miner Res 19:1961-1968

8. Walther F, Fusch C, Radke M et al (2006) Osteoporosis in pediatric patients suffering from chronic inflammatory bowel disease with and without steroid treatment. J Pediatr Gastroenterol Nutr 43:42-51

9. Kalayci AG, Kkansu A, Girgin N et al (2001) Bone mineral density and importance of a gluten-free diet in patients with celiac disease in childhood. Pediatrics 108:e89

10. Barera G, Beccio S, Proverbio MC et al (2004) Longitudinal changes in bone metabolism and bone mineral content in children with celiac disease during consumption of a gluten-free diet. Am J Clin Nutr 79:148-154

11. Tau C, Mautalen C, De Rosa S et al (2006) Bone mineral density in children with celiac disease. Effect of a gluten-free diet. Eur J Clin Nutr 60:358-363

12. Szathmari M, Tulassay T, Arato A et al (2001) Bone mineral content and density in asymptomatic children with celiac disease on a gluten-free diet. Eur J Gastroenterol Hepatol 13:419-424

13. Argao EA, Specker BL, Heubi JE (1993) Bone mineral content in infants and children with chronic cholestatic liver disease. Pediatrics 91:1151-1154

14. Olsen IE, Ittenbach RF, Rovner AJ et al (2005) Deficits in sizeadjusted bone mass in children with Alagille syndrome. J Pediatr Gastroenterol Nutr 40:76-82

15. D'Antiga L, Ballan D, Luisetto G et al (2004) Long-term outcome of bone mineral density in children who underwent a successful liver transplantation. Transplantation 78:899-903

16. Bakr AM (2004) Bone mineral density and bone turnover markers in children with chronic renal failure. Pediatr Nephrol 19:1390-1393

17. Pluskiewicz W, Adamczyk P, Drozdzowska B et al (2005) Skeletal status in adolescents with end-stage renal failure: a longitudinal study. Osteoporos Int 16:289-295

18. Ahmed SF, Russell S, Rashid R et al (2005) Bone mineral content, corrected for height or bone area, measured by DXA is not reduced in children with chronic renal disease or in hypoparathyroidism. Pediatr Nephrol 20:1466-1472

19. Acott PD, Crocker JFS, Wong JA (2003) Decreased bone mineral density in the pediatric renal transplant population. Pediatr Transplant 7:358-363

20. Boot AM, Nauta J, de Jong MC et al (1998) Bone mineral density, bone metabolism and body composition of children with chronic renal failure, with and without growth hormone treatment. Clin Endocrinol 49:665-672
21. Van der Sluis IM, Boot AM, Nauta J et al (2000) Bone density and body composition in chronic renal failure: effects of growth hormone treatment. Pediatr Nephrol 15:221-228

22. Feber J, Cochat P, Braillon P et al (1994) Bone mineral density after renal transplantation in children. J Pediatr 125(6pt1):870-875

23. Klaus G, Paschen C, Wuster C et al (1998) Weight/height-related bone mineral density is not reduced after renal transplantation. Pediatr Nephrol 12:343-348

24. Ellis EN, Floyd-Gimon DM, Berry PL et al (2000) Risk factors for bone mineral density loss in pediatric renal transplant patients. Pediatr Transplant 4:146-150

25. Freundlich M, Alonzo E, Bellorin-Font E et al (2002) Reduced bone mass in children with idiopathic hypercalciuria and in their asymptomatic mothers. Nephrol Dial Transplant 17:1396-1401

26. Garcia-Nieto V, Navarro JF, Monge M et al (2003) Bone mineral density in girls and their mothers with idiopathic hypercalciuria. Nephron Clin Pract 94:c89-c93

27. Penido MG, Lima EM, Marino VS et al (2003) Bone alterations in children with idiopathic hypercalciuria at the time of diagnosis. Pediatr Nephrol 18:133-139

28. Skalova S, Palicka V, Kutilek S (2005) Bone mineral density and urinary $\mathrm{N}$-acetyl-beta-D-glucosaminidase activity in paediatric patients with idiopathic hypercalciuria. Nephrology (Carlton) 10:99-102

29. Bonjour JP, Theintz G, Buchs B et al (1991) Critical years and stages of puberty for spinal and femoral bone mass accumulation during adolescence. J Clin Endocrinol Metab 73:555-563

30. Takahashi Y, Minamitani K, Kobayashi Y et al (1996) Spinal and femoral bone mass accumulation during normal adolescence: comparison with female patients with sexual precocity and with hypogonadism. J Clin Endocrinol Metab 81:1248-1253

31. Unal O, Berberoglu M, Evliyaoglu O et al (2003) Effects on bone mineral density of gonadotropin releasing hormone analogs used in the treatment of central precocious puberty. J Pediatr Endocrinol Metab 16:407-411

32. Saggese G, Baroncelli GI, Bertelloni S et al (1996) The effect of long-term growth hormone $(\mathrm{GH})$ treatment on bone mineral density in children with GH deficiency. Role of GH in the attainment of peak bone mass. J Clin Endocrinol Metab 81:3077-3083

33. Hogler W, Briody J, Moore B et al (2005) Effect of growth hormone therapy and puberty on bone and body composition in children with idiopathic short stature and growth hormone deficiency. Bone 37:642-650

34. Lanes R, Gunczler P, Esaa S et al (2002) The effect of short- and long-term growth hormone treatment on bone mineral density and bone metabolism of prepubertal children with idiopathic short stature: a 3-year study. Clin Endocrinol (Oxf) 57:725-730

35. Baroncelli GI, Bertelloni S, Sodini F et al (2004) Longitudinal changes of lumbar bone mineral density (BMD) in patients with GH deficiency after discontinuation of treatment at final height; timing and peak values for lumbar BMD. Clin Endocrinol (Oxf) 60:175-184

36. Baroncelli GI, Saggese G (2005) Effect of GH treatment on bone mass in children with GH deficiency. J Endocrinol Invest 28(10 Suppl):23-27

37. Moyer-Mileur LJ, Dixon SB, Quick JL et al (2004) Bone mineral acquisition in adolescents with type 1 diabetes. J Pediatr 145:662-669

38. Gunczler P, Lanes R, Paz-Martinez V et al (1998) Decreased lumbar spine bone mass and low bone turnover in children and adolescents with insulin dependent diabetes mellitus followed longitudinally. J Pediatr Endocrinol Metab 11:413-419

39. Karaguzel G, Akcurin S, Ozdem S et al (2006) Bone mineral density and alterations of bone metabolism in children and adolescents with type 1 diabetes mellitus. J Pediatr Endocrinol Metab 19:805-814 
40. Valerio G, del Puente A, Esposito-del Puente A et al (2002) The lumbar bone mineral density is affected by long-term poor metabolic control in adolescents with type 1 diabetes mellitus. Horm Res 58:266-272

41. Heap J, Murray MA, Miller SC et al (2004) Alterations in bone characteristics associated with glycemic control in adolescents with type 1 diabetes mellitus. J Pediatr 144:55-62

42. Mora S, Saggion F, Russo G et al (1996) Bone density in young patients with congenital adrenal hyperplasia. Bone 18:337-340

43. Guo CY, Weetman AP, Eastell R (1996) Bone turnover and bone mineral density in patients with congenital adrenal hyperplasia. Clin Endocrinol (Oxf) 45:535-541

44. King JA, Wisniewski AB, Bankowski BJ et al (2006) Long-term corticosteroid replacement and bone mineral density in adult women with classical congenital adrenal hyperplasia. J Clin Endocrinol Metab 91:865-869

45. Di Somma C, Pivonello R, Loche S et al (2002) Severe impairment of bone mass and turnover in Cushing's disease: comparison between childhood-onset and adulthood-onset disease. Clin Endocrinol (Oxf) 56:153-158

46. Di Somma C, Pivonello R, Loche S et al (2003) Effect of 2 years of cortisol normalization on the impaired bone mass and turnover in adolescent and adult patients with Cushing's disease: a prospective study. Clin Endocrinol (Oxf) 58:302-308

47. Shoepe HA, Snow CM (2005) Oral contraceptive use in young women is associated with lower bone mineral density than that of controls. Osteoporos Int 16:1538-1544

48. Cromer BA, Stager M, Bonny A et al (2004) Depot medroxyprogesterone acetate, oral contraceptives and bone mineral density in a cohort of adolescent girls. J Adolesc Health 35:434-441

49. Cromer BA, Blair JM, Mahan JD et al (1996) A prospective comparison of bone density in adolescent girls receiving depot medroxyprogesterone acetate (Depo-Provera), levonorgestrel (Norplant), or oral contraceptives. J Pediatr 129:671-676

50. Banks E, Berrington A, Casabonne D (2001) Overview of the relationship between use of progestogen-only contraceptives and bone mineral density. BJOG 108:1214-1221

51. Cromer BA, Lazebnik R, Rome E et al (2005) Double-blinded randomized controlled trial of estrogen supplementation in adolescent girls who receive depot medroxyprogesterone acetate for contraception. Am J Obstet Gynecol 192:42-47

52. Resch H, Newrkla S, Grampp S et al (2000) Ultrasound and xray-based bone densitometry in patients with anorexia nervosa. Calcif Tissue Int 66:338-341

53. Soyka LA, Misra M, Frenchman A et al (2002) Abnormal bone mineral accrual in adolescent girls with anorexia nervosa. J Clin Endocrinol Metab 87:4177-4185

54. Milos G, Spindler A, Ruegsegger P et al (2005) Cortical and trabecular bone density and structure in anorexia nervosa. Osteoporos Int 16:783-790

55. Biller BM, Saxe V, Herzog DB et al (1989) Mechanisms of osteoporosis in adult and adolescent women with anorexia nervosa. J Clin Endocrinol Metab 68:548-554

56. Kooh SW, Noriega E, Leslie K et al (1996) Bone mass and soft tissue composition in adolescents with anorexia nervosa. Bone 19:181-188

57. Seeman E, Szmukler GI, Formica C et al (1992) Osteoporosis in anorexia nervosa: the influence of peak bone density, bone loss, oral contraceptive use, and exercise. J Bone Miner Res 7:1467-1474

58. Kooh SW, Brnjac L, Ehrlich RM et al (1996) Bone mass in children with congenital hypothyroidism treated with thyroxine since birth. J Pediatr Endocrinol Metab 9:59-62

59. Leger J, Ruiz JC, Guibourdenche J et al (1997) Bone mineral density and metabolism in children with congenital hypothyroidism after prolonged L-thyroxine therapy. Acta Paediatr $86: 704-710$
60. Salerno M, Lettiero T, Puente AE et al (2004) Effect of longterm L-thyroxine treatment on bone mineral density in young adults with congenital hypothyroidism. Eur J Endocrinol 151: 689-694

61. Saggese G, Bertelloni S, Baroncelli GI et al (1996) Bone mineral density in adolescent females treated with L-thyroxine: a longitudinal study. Eur J Pediatr 155:452-457

62. Lucidarme N, Ruiz JC, Czernichow P et al (2000) Reduced bone mineral density at diagnosis and bone mineral recovery during treatment in children with Graves' disease. J Pediatr 137:56-62

63. Sood M, Hambleton G, Super M et al (2001) Bone status in cystic fibrosis. Arch Dis Child 84:516-520

64. Haslam RH, Borovnicar DJ, Stroud DB et al (2001) Correlates of prepubertal bone mineral density in cystic fibrosis. Arch Dis Child 85:166-171

65. Hardin DS, Arumugam R, Seilheimer DK et al (2001) Normal bone mineral density in cystic fibrosis. Arch Dis Child 84:363-368

66. Buntain HM, Greer RM, Schluter PJ et al (2004) Bone mineral density in Australian children, adolescents and adults with cystic fibrosis: a controlled cross sectional study. Thorax 59:149-155

67. Haworth CS, Selby PL, Webb AK et al (1999) Low bone mineral density in adults with cystic fibrosis. Thorax 54:961-967

68. Henderson RC, Madsen CD (1996) Bone density in children and adolescents with cystic fibrosis. J Pediatr 128:28-39

69. Haworth CS, Selby PL, Horrocks AW et al (2002) A prospective study of change in bone mineral density over one year in adults with cystic fibrosis. Thorax 57:719-723

70. Bhudhikanok GS, Wang MC, Marcus R et al (1998) Bone acquisition and loss in children and adults with cystic fibrosis: a longitudinal study. J Pediatr 33:18-27

71. Aris RM, Lester GE, Renner JB et al (2000) Efficacy of pamidronate for osteoporosis in patients with cystic fibrosis following lung transplantation. Am J Respir Crit Care Med 162:941-946

72. Aris RM, Lester GE, Caminiti M et al (2004) Efficacy of alendronate in adults with cystic fibrosis with low bone density. Am J Respir Crit Care Med 169:77-82

73. Haworth CS, Selby PL, Adams JE et al (2001) Effect of intravenous pamidronate on bone mineral density in adults with cystic fibrosis. Thorax 56:314-316

74. Boot AM, de Jongste JC, Verberne AA et al (1997) Bone mineral density and bone metabolism of prepubertal children with asthma after long-term treatment with inhaled corticosteroids. Pediatr Pulmonol 24:379-384

75. Agertoft L, Pedersen S (1998) Bone mineral density in children with asthma receiving long-term treatment with inhaled budesonide. Am J Respir Crit Care Med 157:178-183

76. Bahceciler NN, Sezgin G, Nursoy MA et al (2002) Inhaled corticosteroids and bone density of children with asthma. J Asthma 39:151-157

77. Altzntas DU, Karakoc GB, Can S et al (2005) The effects of long term use of inhaled corticosteroids on linear growth, adrenal function and bone mineral density in children. Allergol Immunopathol 33:204-209

78. Allen HD, Thong IG, Clifton-Bligh P et al (2000) Effects of high-dose inhaled corticosteroids on bone metabolism in prepubertal children with asthma. Pediatr Pulmonol 29:188-193

79. Harris M, Hauser S, Nguyen TV et al (2001) Bone mineral density in prepubertal asthmatics receiving corticosteroid treatment. J Paediatr Child Health 37:67-71

80. Brinker MR, Thomas KA, Meyers SJ et al (1998) Bone mineral density of the lumbar spine and proximal femur is decreased in children with sickle cell anemia. Am J Orthop 27:43-49

81. Soliman AT, Bererhi H, Darwish A et al (1998) Decreased bone mineral density in prepubertal children with sickle cell disease: correlation with growth parameters, degree of siderosis and secretion of growth factors. J Trop Pediatr 44:194-198 
82. Lal A, Fung EB, Pakbaz Z et al (2006) Bone mineral density in children with sickle cell anemia. Pediatr Blood Cancer 47: 901-906

83. Buison AM, Kawchak DA, Schall JI et al (2005) Bone area and bone mineral content deficits in children with sickle cell disease. Pediatrics 116:943-949

84. Ahmed S, Siddique S, Rice T et al (2006) High prevalence and correlates of low bone mineral density in young adults with sickle cell disease. Am J Hematol 81:236-241

85. Vogiatzi MG, Autio KA, Schneider R et al (2004) Low bone mass in prepubertal children with thalassemia major: insights into the pathogenesis of low bone mass in thalassemia. J Pediatr Endocrinol Metab 17:1415-1421

86. Benigno V, Bertelloni S, Baroncelli GI et al (2003) Effects of thalassemia major on bone mineral density in late adolescence. $\mathrm{J}$ Pediatr Endocrinol Metab 16:337-342

87. Barnes C, Wong P, Egan B et al (2004) Reduced bone density among children with severe hemophilia. Pediatrics 114:177-181

88. Gallacher SJ, Deighan C, Wallace AM et al (1994) Association of severe haemophilia A with osteoporosis: a densitometric and biochemical study. Q J Med 87:181-186

89. Arikoski P, Komulainen J, Voutilainen R et al (1998) Reduced bone mineral density in long-term survivors of childhood acute lymphoblastic leukemia. J Pediatr Hematol Oncol 20:234-240

90. Brennan BM, Rahim A, Adams JA et al (1999) Reduced bone mineral density in young adults following cure of acute lymphoblastic leukaemia in childhood. Br J Cancer 79:1859-1863

91. van der Sluis IM, van den Heuvel-Eibrink MM, Hahlen K et al (2000) Bone mineral density, body composition, and height in longterm survivors of acute lymphoblastic leukemia in childhood. Med Pediatr Oncol 35:415-420

92. Boot AM, van den Heuvel-Eibrink MM, Hahlen K et al (1999) Bone mineral density in children with acute lymphoblastic leukaemia. Eur J Cancer 35:1693-1697

93. Marinovic D, Dorgeret S, Lescoeur B et al (2005) Improvement in bone mineral density and body composition in survivors of childhood acute lymphoblastic leukemia: a 1-year prospective study. Pediatrics 116:e102-e108

94. Jarfelt M, Fors H, Lannering B et al (2006) Bone mineral density and bone turnover in young adult survivors of childhood acute lymphoblastic leukaemia. Eur J Endocrinol 154:303-309

95. Aisenberg J, Hsieh K, Kalaitzoglou G (1998) Bone mineral density in young adult survivors of childhood cancer. Hematol Oncol 20:241-245

96. Vassilopoulou-Sellin R, Brosnan P, Delpassand A et al (1999) Osteopenia in young adult survivors of childhood cancer. Med Pediatr Oncol 32:272-278

97. Nysom K, Holm K, Michaelsen KF et al (2001) Bone mass after treatment of malignant lymphoma in childhood. Med Pediatr Oncol 37:518-524

98. Kelly J, Damron T, Grant W et al (2005) Cross-sectional study of bone mineral density in adult survivors of solid pediatric cancers. J Pediatr Hematol Oncol 27:248-253

99. Ruza E, Sierrasesumaga L, Azcona C et al (2006) Bone mineral density and bone metabolism in children treated for bone sarcomas. Pediatr Res 59:866-871

100. Odame I, Duckworth J, Talsma D et al (2006) Osteopenia, physical activity and health-related quality of life in survivors of brain tumors treated in childhood. Pediatr Blood Cancer 46:357-362

101. Harcke HT, Taylor A, Bachrach S et al (1998) Lateral femoral scan: an alternative method for assessing bone mineral density in children with cerebral palsy. Pediatr Radiol 28:241-246

102. Henderson RC, Lark RK, Newman JE et al (2002) Pediatric reference data for dual $\mathrm{x}$-ray absorptiometric measures of normal bone density in the distal femur. AJR 178:439-443
103. Henderson RC, Lin PP, Greene WB (1995) Bone-mineral density in children and adolescents who have spastic cerebral palsy. J Bone Joint Surg Am 77:1671-1681

104. Henderson RC, Lark RK, Gurka MJ et al (2002) Bone density and metabolism in children and adolescents with moderate to severe cerebral palsy. Pediatrics 110:1-10

105. Henderson RC, Kairalla JA, Barrington JW et al (2005) Longitudinal changes in bone density in children and adolescents with moderate to severe cerebral palsy. J Pediatr 146:769-775

106. Henderson RC, Lark RK, Kecskemethy HH et al (2002) Bisphosphonates to treat osteopenia in children with quadriplegic cerebral palsy: a randomized, placebo-controlled clinical trial. J Pediatr 141:644-651

107. Bachrach SJ, Kecskemethy HH, Harcke HT et al (2006) Pamidronate treatment and posttreatment bone density in children with spastic quadriplegic cerebral palsy. J Clin Densitom 9:167-174

108. Quan A, Adams R, Ekmark E et al (1998) Bone mineral density in children with myelomeningocele. Pediatrics 102:e34

109. Quan A, Adams R, Ekmark E et al (2003) Bone mineral density in children with myelomeningocele; effect of hydrochlorothiazide. Pediatr Nephrol 18:929-933

110. Valtonen KM, Goksor LA, Jonsson O et al (2006) Osteoporosis in adults with meningomyelocele: an unrecognized problem at rehabilitation clinics. Arch Phys Med Rehabil 87:376-382

111. Pepmueller PH, Cassidy JT, Allen SH et al (1996) Bone mineralization and bone mineral metabolism in children with juvenile rheumatoid arthritis. Arthritis Rheum 39:746-757

112. Pereira RM, Corrente JE, Chahade WH et al (1998) Evaluation by dual x-ray absorptiometry (DXA) of bone mineral density in children with juvenile chronic arthritis. Clin Exp Rheumatol 16:495-501

113. Lien G, Flato B, Haugen M et al (2003) Frequency of osteopenia in adolescents with early-onset juvenile idiopathic arthritis. Arthritis Rheum 48:2214-2223

114. Henderson CJ, Cawkwell GD, Specker BL et al (1997) Predictors of total body bone mineral density in non-corticosteroid-treated prepubertal children with juvenile rheumatoid arthritis. Arthritis Rheum 40:1967-1975

115. Henderson CJ, Specker BL, Sierra RI et al (2000) Total-body bone mineral content in non-corticosteroid-treated postpubertal females with juvenile rheumatoid arthritis. Arthritis Rheum 43:531-554

116. Mul D, van Suijlekom-Smit LW, ten Cate R et al (2002) Bone mineral density and body composition and influencing factors in children with rheumatic diseases treated with corticosteroids. J Pediatr Endocrinol Metab 15:187-192

117. Bianchi ML, Cimaz R, Galbiati E et al (1999) Bone mass change during methotrexate treatment in patients with juvenile rheumatoid arthritis. Osteoporos Int 10:20-25

118. Trapani S, Civinini R, Ermini M et al (1998) Osteoporosis in juvenile systemic lupus erythematosus: a longitudinal study on the effect of steroids on bone mineral density. Rheumatol Int 18:45-49

119. Castro TC, Terreri MT, Szejnfeld VL et al (2002) Bone mineral density in juvenile systemic lupus erythematosus. Braz J Med Biol Res 35:1159-1163

120. Larson CM, Henderson RC (2000) Bone mineral density and fractures in boys with Duchenne muscular dystrophy. J Pediatr Orthop 20:71-74

121. Bianchi ML, Mazzanti A, Galbiati E et al (2003) Bone mineral density and bone metabolism in Duchenne muscular dystrophy. Osteoporos Int 14:761-776

122. Hawker GA, Ridout R, Harris VA et al (2005) Alendronate in the treatment of low bone mass in steroid-treated boys with Duchenne's muscular dystrophy. Arch Phys Med Rehabil 86:284-288 
123. Stewart WA, Acott PD, Salisbury SR et al (2003) Bone mineral density in juvenile dermatomyositis. Arthritis Rheum 48:2294-2298

124. Castro TC, Terreri MT, Szejnfeld VL et al (2005) Bone mineral density of Brazilian girls with juvenile dermatomyositis. Braz J Med Biol Res 38:309-313

125. Lund AM, Molgaard C, Muller J et al (1999) Bone mineral content and collagen defects in osteogenesis imperfecta. Acta Paediatr 88:1083-1088

126. Rauch F, Glorieux FH (2005) Bisphosphonate treatment in osteogenesis imperfecta: which drug, for whom, for how long? Ann Med 37:295-302

127. Zacharin M, Kanumakala S (2004) Pamidronate treatment in less severe forms of osteogenesis imperfecta. J Pediatr Endocrinol Metab 17:1511-1517

128. Gatti D, Antoniazzi F, Prizzi R et al (2005) Intravenous neridronate in children with osteogenesis imperfecta: a randomized controlled study. J Bone Miner Res 20:758763

129. Arikoski P, Silverwood B, Tillmann V et al (2004) Intravenous pamidronate in children with moderate to severe osteogenesis imperfecta: assessment of indices of dual-energy X-ray absorptiometry and bone metabolic markers during the first year of therapy. Bone 34:539-546

130. Letocha AD, Cintas HL, Troendle JF et al (2005) Controlled trial of pamidronate in children with types III and IV osteogenesis imperfecta confirms vertebral gains but not short-term functional improvement. J Bone Miner Res 20:977-986

131. Zeitlin L, Rauch F, Plotkin H et al (2003) Height and weight development during four years of therapy with cyclical intravenous pamidronate in children and adolescents with osteogenesis imperfecta types I, III, and IV. Pediatrics 111(5 Pt 1): $1030-1036$ 